\section{Apple Compositional and Peel Color Differences Resulting from Canopy Microclimate Affect Consumer Preference for Eating Quality and Appearance}

\author{
Esnath T. Hamadziripi and Karen I. Theron \\ Department of Horticultural Science, University of Stellenbosch, Private Bag \\ X1, Matieland, 7602, Stellenbosch, South Africa
}

\author{
Magdalena Muller \\ Department of Food Science, University of Stellenbosch, Private Bag X1, \\ Matieland, 7602, Stellenbosch, South Africa
}

Willem J. Steyn ${ }^{1}$

Department of Horticultural Science, University of Stellenbosch, Private Bag X1, Matieland, 7602, Stellenbosch, South Africa; and Hortgro Science, P.O. Box 12789, Die Boord 7613, South Africa

Additional index words. antioxidant capacity, flavor, fruit color, Malus domestica, microclimate, texture

\begin{abstract}
We hypothesized that the microclimate at different positions in the tree canopy may affect the appearance, eating quality, and consumer preference for apple fruit. Hence, the aim of this study was to evaluate the internal and external quality of inner and outer canopy apples in relation to consumer preference for the eating quality and appearance of these fruit. We determined peel color, flesh firmness, percentage starch breakdown, soluble solids concentration (TSS), titratable acidity (TA), and dry matter concentration (DMC) for inner and outer canopy 'Starking', 'Golden Delicious', and 'Granny Smith' from the Ceres region in South Africa in the 2009-10 and 2010-11 seasons. We also determined reducing sugars, total phenolics, and total antioxidant capacity in the 2009-10 season. A trained panel assessed the sensory characteristics of fruit while consumers were asked to indicate their liking for the eating quality and appearance of fruit. Outer canopy fruit of all three cultivars had higher antioxidant capacity, TSS, DMC, lower TA, and were generally sweeter than inner canopy fruit. Consumers could discern eating quality differences and generally preferred the eating quality of outer canopy fruit. The appearance of outer canopy fruit was not preferred in the "green" cultivars, probably as a result of the unfamiliarity of consumers with such fruit. Consumers did, however, prefer the redder outer canopy to the less red inner canopy 'Starking' fruit. The redness of 'Starking' fruit in this study can therefore be seen as a true signal of eating quality, i.e., the redder the fruit, the better the eating quality, and this would probably apply to other fully red and bicolored apple cultivars. Hence, the classification of red cultivars into different quality classes based on the extent of red color development seems justified from an eating quality perspective. In contrast, blushed outer canopy 'Granny Smith' and 'Golden Delicious' are culled for aesthetic reasons. It might be possible to develop a niche local market for these blushed fruit based on their better eating quality. Our data were generated in older orchards with trees planted at low density and with large canopies. Planer, two-dimensional canopies are likely to reduce the differences between inner and outer canopy fruit. Differences in macroclimate or in fruit maturity between seasons may also have an overbearing effect on fruit quality parameters compared with canopy microclimatic conditions.
\end{abstract}

Fruit are exposed to different microclimatic conditions determined by their position in the tree canopy. The two main factors that vary highly in the canopy are light and temperature. Inner canopy fruit experience lower light and temperature conditions compared with outer canopy fruit. In a 'Granny Smith' orchard with a canopy width of $\approx 2.5 \mathrm{~m}$, inner canopy fruit received only $2 \%$ (33 $\left.\mu \mathrm{mol} \cdot \mathrm{m}^{-2} \cdot \mathrm{s}^{-1}\right)$ of full sun photosynthetic photon within the tree (Johnson and Ridout, 2000), and this may relate to exposure to different microclimatic environments.

Fruit quality is of paramount importance because it forms the basis of consumer satisfaction in fresh produce (Jaeger et al., 2002). The first assessment of fruit by the consumer is of a visual nature. Pigment composition determines the appearance of the fruit, which from an aesthetic and from a quality-signaling perspective has an important function in consumer acceptability (Steyn, 2012). Hence, peel color is an important quality attribute in determining consumer acceptance of apples (Telias et al., 2011). The red color in apple peel is for many apple cultivars one of the most important factors in consumer acceptance (Saure, 1990). The intensity of red blush on the apple peel is an important consideration for the consumer in purchasing fruit and is also used as grading standards in retail outlets and when fruit is packed (Iglesias et al., 2008). Fruit may be downgraded as a result of insufficient red color development. However, in some cases, red pigmentation is an undesirable feature; for instance, any trace of blush in 'Granny Smith' apples results in the downgrading of the fruit (Hirst et al., 1990). Consumers use peel color to identify apple cultivars as well as their eating quality preferences; for example, consumers were found to associate red-colored apples with sweet sensory descriptors and green apples with grassy, acidic, or sour sensory descriptors (Daillant-Spinnler et al., 1996).

Upon tasting, internal quality characteristics such as flavor, sweetness, sourness, and texture attributes are also determinants of consumer preference in apples (Jaeger et al., 1998). Consumer acceptability based on how the product tastes shows that soluble solids concentration is a useful tool to determine the minimum acceptable eating quality and is a satisfactory indicator of eating quality in many fruits including peaches, nectarine, and apples (Crisosto et al., 2003; Harker et al., 2002). Apple taste is more accurately reflected by the concentration of soluble solids and acids and the balance between these two quality parameters (Jackson, 2003). DMC is also an important holistic measurement because it is an indicator of physiological and metabolic processes that contribute to the final composition of the fruit (Harker et al., 2009). Apples with higher DMC have been found to have higher consumer preference (Palmer et al., 2010).

Apart from gustatory reasons, consumers indicate that they eat apples because they are healthy and promote long life (Jaeger and MacFie, 2001). Apples are a rich source of phenolic compounds (Boyer and Liu, 2004). Phenolic compounds are an important dietary component as a result of their anticancer and chemopreventive properties (Kang et al., 2004; Santos-Buelga and Scalbert, 2000). Phenolics as a group constitute the largest fraction of the total antioxidant capacity of apple fruit (Lee et al., 2003). Total phenolics correlated strongly with total antioxidant 
activity in the flesh $(r=0.91)$ and peel $(r=$ 0.98 ) of seven apple cultivars (Drogoudi et al., 2008). Antioxidants play an important role in preventing free radicals from causing oxidative damage, which is linked to many diseases in humans (Dragsted et al., 1993; Lila, 2004). Apples contain relatively low levels of ascorbic acid compared with other fruits (Leong and Shui, 2002). However, consumers associate ascorbic acid with health benefits (Jaeger and MacFie, 2001) and in that regard, it is an important component of any fruit.

This study was conducted over the 200910 and 2010-11 seasons to investigate the chemical, textural, sensory, and consumer preference differences that may exist between inner and outer canopy fruit of 'Starking', 'Golden Delicious', and 'Granny Smith' apples and how such differences, if present, would affect consumer preference for apple eating quality and appearance. Of particular interest were the chemical components that affect the appearance, eating quality, and nutritional value - or perceptions thereof - of the fruit. These findings would indicate whether differentiation between inner and outer canopy fruit could increase consumer satisfaction. Results would also indicate the potential to develop a niche local market for blushed 'Granny Smith' and 'Golden Delicious' apples.

\section{Materials and Methods}

Plant material and experimental design. Three commercial apple cultivars were used for this study, viz. 'Granny Smith', which is dark green at harvest maturity, 'Golden Delicious', which is yellow-green at harvest maturity, and 'Starking', which vary from red-striped to green depending on canopy position. Fruit were sourced from Vastrap Farm in the Witzenberg Valley, Ceres (lat. $33^{\circ} 23^{\prime}$ S, long. $19^{\circ} 19^{\prime}$ E), Western Cape, South Africa. In the 2009-10 season, 'Golden Delicious' and 'Starking' were harvested on 1 Mar. 2010 and 'Granny Smith' on 8 Apr. 2010. In the 2010-11 season, 'Golden Delicious', 'Starking', and 'Granny Smith' were harvested on $28 \mathrm{Feb}$., 22 Mar., and 5 Apr. 2011, respectively. These harvesting dates immediately preceded the commercial harvesting of the respective orchards in the 2009-10 and 2010-11 seasons.

\footnotetext{
Received for publication 14 Nov. 2013. Accepted for publication 10 Jan. 2014.

This paper forms part of a thesis submitted by Esnath Hamadziripi in fulfilling an MScAgric degree requirement. This material is based on work supported by the Food Security Initiative of the HOPE project of the University of Stellenbosch. We thank Mardé Booyse for statistical analysis of the data.

Any opinions, findings, and conclusions or recommendations expressed in this material are those of the authors.

${ }^{1}$ To whom reprint requests should be addressed; e-mailwiehann@hortgro.co.za.
}

The 'Granny Smith' and the 'Golden Delicious' orchards were planted on seedling rootstock in a north-south row orientation at a spacing of $6.71 \mathrm{~m} \times 3.35 \mathrm{~m}$ in 1974 and 1960, respectively. 'Starking' on seedling rootstock was planted in 1974 at a spacing of $5 \mathrm{~m} \times 3 \mathrm{~m}$ and similar row orientation as mentioned. These older open vase orchards were selected so as to maximize the contrast between inner and outer canopy fruit. For 'Granny Smith' and 'Golden Delicious', only fruit with red blush, mainly found at the top outer positions of the tree canopy, were harvested as the outer canopy fruit. The study was laid out to a complete randomized design with 10 replications for each canopy position. Fruit harvested from three consecutive trees represented a replicate and 15 inside and outside fruit were harvested for each replicate.

Maturity analysis was carried out immediately after harvest as assessment of the percentage of starch breakdown. One fruit from each replicate (i.e., 10 fruit per canopy position) was randomly selected and assessed to ensure that the inner and outer canopy fruit were of comparable maturity. Fruit were stored at $-0.5^{\circ} \mathrm{C}$ before physical measurements, chemical analysis, sensory analysis, and consumer preference studies, all conducted within 1 month after harvest. Of the 14 fruit remaining per replicate, four were allocated for the consumer panel, five were allocated for the trained panel, and five fruit were set aside for physical and chemical analyses. Peel color and flesh firmness were measured for each of the five fruit, where after fruit samples were pooled for assessment of DMC. After flesh samples were taken for assessment of the DMC, peel samples and the remaining flesh samples were flash-frozen in liquid nitrogen and transferred to storage at $-80{ }^{\circ} \mathrm{C}$ for assessment of peel pigments, sugars, ascorbic acid, total phenolics, and antioxidant capacity.

Light and temperature measurements. Light received by fruit in the inner and outer canopy in the 'Starking' orchard was measured every $2 \mathrm{~h}$ from $0900 \mathrm{HR}$ to $1700 \mathrm{HR}$ on 1 Mar. 2010 as per Fouché et al. (2010). Shaded fruit from the inner canopy and fruit fully exposed to sunlight on the western side of the tree row were selected for inner and outer canopy measurements, respectively. Measurements were carried out using a quantum sensor attached to a light meter (LI-250; LICOR, Lincoln, NE) that was held above the fruit with the sensor orientated toward the sun. Peel temperatures of inside and outside canopy fruit were also measured on the fruit surface perpendicular to the current position of the sun at the same time intervals as the light measurements using a high-performance infrared thermometer (Rayner MX4; Raytek Corporation, Santa Cruz, CA). Measurements were taken on 10 trees in the same orchards from which fruit were harvested for the experiment.

Physicochemical measurements. Each fruit was weighed on an electronic balance and fruit diameter was determined using a set of digital Mitutoyo calipers (Mitutoyo, Kana- gawa, Japan). The color (hue angle) of each apple was measured using a colorimeter (Konica CR-400; Minolta Co. Ltd., Tokyo, Japan). On each fruit, hue angle was recorded at the reddest and least red (or greenest) position. The extent of red color development for the respective canopy positions is evident from the representative pictures presented in Figure 1. Percentage DMC was determined by weighing a fresh sample of fruit and ovendrying the fruit over a period of $72 \mathrm{~h}$ at $45^{\circ} \mathrm{C}$. Fruit were weighed immediately and returned into the oven for a further $24 \mathrm{~h}$ and re-weighed to ensure all the moisture had evaporated. The following formula was used to calculate DMC as a percentage: $\mathrm{DMC}(\%)=($ dry weight $/$ fresh weight) $* 100$.

The percentage starch breakdown of the apples was determined by placing half of the apple in an iodine solution and evaluating the starch breakdown using a starch conversion chart for pome fruit (Unifruco Research Services, Bellville, South Africa). Flesh firmness was measured using a penetrometer [Fruit Texture Analyser; GUSS Manufacturing (Pyt) Ltd., Strand, South Africa] fitted with an 11-mm diameter probe. Two readings were taken on opposite peeled sides of the fruit approximately halfway between the calyx and the stem. Slices of apple were placed in a juice extractor and the juice was used to determine the TSS concentration and the TA. TSS was measured using a calibrated handheld refractometer (TSS $0 \%$ to $32 \%$, Model N1; Atago, Tokyo, Japan). TA was measured using an automated titrator (Tritino 719S and Sample Changer 674; Metrohm Ltd., Herisau, Switzerland) by titrating $5 \mathrm{~g}$ of juice from each apple sample with $0.1 \mathrm{M}$ $\mathrm{NaOH}$ to a $\mathrm{pH}$ of 8.2 . The TA is expressed as percentage malic acid.

Pigment analysis. Chlorophylls and carotenoids were extracted from a $0.5 \mathrm{-g}$ fresh peel sample in $3 \mathrm{~mL}$ of cold $100 \%$ acetone as the extraction solvent. The pigments were quantified using a mass spectrophotometer [Cary 50 Bio; Varian, Australia (PTY) Ltd., Melbourne, Australia] measuring absorbance at 470, 645, and $670 \mathrm{~nm}$. The extinction coefficients of Lichtenthaler (1987) were used to calculate the chlorophyll and carotenoid concentrations in $\mu \mathrm{g} \cdot \mathrm{g}^{-1}$ fresh weight (FW) peel. Anthocyanins were extracted from $0.2 \mathrm{~g}$ of fresh frozen peel samples in $5 \mathrm{~mL}$ methanol and $3 \mathrm{M} \mathrm{HCl}(95: 5 \mathrm{v} / \mathrm{v})$ as the extraction solvent. They were quantified using a mass spectrophotometer [Cary 50 Bio; Varian, Australia (PTY) Ltd.] measuring absorbance at $530 \mathrm{~nm}$ and $635 \mathrm{~nm}$. The following equation was used to remove chlorophyll absorbance peaks: absorption at $530 \mathrm{~nm}-$ $0.24 \times$ absorption at $653 \mathrm{~nm}$ (Mancinelli et al., 1975). The anthocyanin concentrations were calculated from the standard curve of cyanidin3-galactoside (Carl Roth, Karlsruhe, Germany) and were expressed in $\mu \mathrm{g} \cdot \mathrm{g}^{-1} \mathrm{FW}$ peel.

Sugar concentration. Sugars were analyzed by high-performance liquid chromatography (HPLC) (Agilent 1100 series; Hewlett Packard) with a photo diode array detector and refractive index detector series. The sugars 

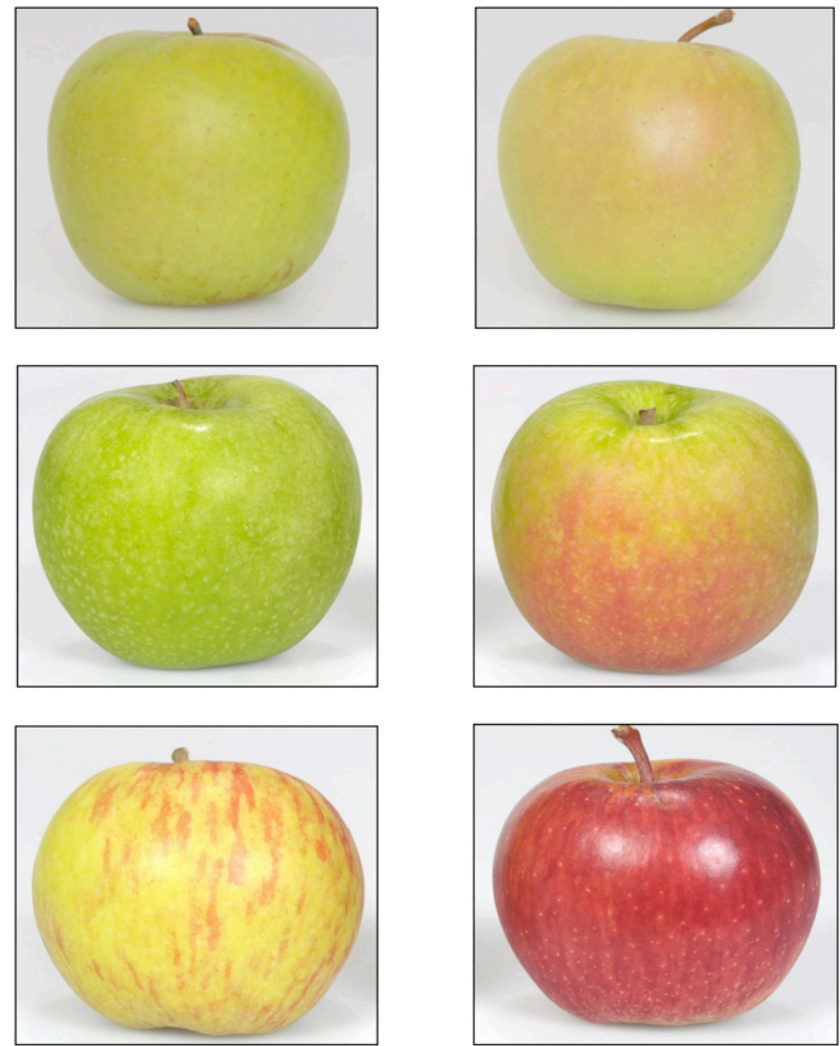

Fig. 1. Images of inner and outer canopy fruit of 'Golden Delicious' (A), 'Granny Smith' (B), and 'Starking' (C) harvested from Vastrap, Ceres, South Africa.

were separated using a $300 \times 7.8$ transgenomic ion 300 column (Phenomenex). One gram of fresh apple samples was weighed out and extracted in $1.5 \mathrm{~mL}$ solvent of $2 \mathrm{~g} \cdot \mathrm{L}^{-1}$ mannitol solution. Sucrose, glucose, fructose, and sorbitol were identified and quantified by comparing their retention times and peak heights with $2 \mathrm{~g} \cdot \mathrm{L}^{-1}$ mannitol, which also served as the internal standard. The values of the individual sugars were added together to obtain the total sugar concentration, which is presented in this article.

Ascorbic acid concentration. Ascorbic acid was analyzed on a HPLC (Agilent 1100 series; Hewlett Packard) using a C18 pre-column with $4.6 \times 12.5 \mathrm{~mm}, 5 \mu \mathrm{m}$, and a main column $250 \times 4.6 \mathrm{~mm}$ (Capcell Pak, $5 \mu$ C18 MG; Phenomenex). A computer program (Chemstation LC 3D, Rev.B.01.03; Agilent) was used for identification and quantification of ascorbic acid peaks against reference standards. Three grams of apple flesh and $1 \mathrm{~g}$ of apple peel were weighed and $6 \mathrm{~mL}$ and $3 \mathrm{~mL}$ extraction buffer $(100 \mathrm{~mm}$ EDTA) added to each sample, respectively. The samples were vortexed and stored at $4{ }^{\circ} \mathrm{C}$ for $1 \mathrm{~h}$ before being centrifuged (Eppendorf 5417R; Merck, Hamburg, Germany) at $20,000 \mathrm{rpm}$ for $15 \mathrm{~min}$ at $4{ }^{\circ} \mathrm{C}$. Six hundred microliters of the supernatant were decanted and to $40 \mu \mathrm{L}$ of this supernatant, $20 \mu \mathrm{L}$ of reduction solution dithiothreitol and Trizma base $(1: 1 \mathrm{v} / \mathrm{v})$ were added. The sample was vortexed and allowed to stand for $20 \mathrm{~min}$.
Finally, $20 \mu \mathrm{L}$ of a stop solution $(8.5 \%$ orthophosphoric acid) was added to the solution and vortexed well before analysis on the HPLC. The ascorbic acid peak was identified by retention time and spectral comparison with a prepared ascorbic acid standard (SigmaAldrich, Steinheim, U.K.), which was used to calibrate and determine the concentration of ascorbic acid.

Total phenolic concentration. Total phenolics were quantified using a slightly modified Folin-Ciocalteu method (Slinkard and Singleton, 1977) measuring absorbance at $750 \mathrm{~nm}$. Four hundred fifty microliters of 1:6 Folin-Ciocalteu reagent was added to $50 \mu \mathrm{L}$ of apple flesh extract and a further $500 \mu \mathrm{L}$ sodium bicarbonate was added after a 5-min waiting step. This was followed by a 90-min waiting step. Peel samples were diluted using a dilution of 1:9 with the extraction solvent. The absorbance was measured at $750 \mathrm{~nm}$ on the spectrophotometer [Cary 50 Bio; Varian, Australia (PTY) Ltd.]. The phenolics were quantified using a gallic acid standard curve.

Total antioxidant capacity. Total antioxidant capacity was determined using a slightly modified method of Vinotur and Rodov (2006) where the activity of hydrophilic and lipophilic antioxidants was evaluated as scavenging capacity toward the ion radical of $2,2^{\prime}$ azino-bis-(3-ethylbenzthiazoline-6-sulphonic acid) (ABTS) and expressed as Trolox (6hydrooxy-2,5,7,8-tetramethylchroman-2- carboxylic acid) equivalent antioxidant capacity. For the apple flesh sample, $1 \mathrm{~g} \mathrm{FW}$ of apple flesh was used for extraction of the antioxidants, whereas for apple peel, $0.5 \mathrm{~g}$ FW was used. Ten microliters of lipophilic and hydrophilic extracts were pipetted into plastic cuvettes followed by $0.990 \mathrm{~mL}$ of the pre-prepared $\mathrm{ABTS}^{+}$radical. The sample was incubated for $15 \mathrm{~min}$ (during which decolorization of the $\mathrm{ABTS}^{+}$by the antioxidants was observed) before analysis against $10 \mathrm{~mm}$ Trolox standards on the spectrophotometer [Cary 50 Bio; Varian, Australia (PTY) Ltd.] at $734 \mathrm{~nm}$.

Descriptive sensory analysis. A sensory panel consisting of eight judges was used for the sensory analysis. The judges were trained using the consensus method (Lawless and Heymann, 2010). The panel used a 100-mm unstructured line scale, ranging from $0 \%$ on the far left and $100 \%$ on the far right end, to analyze peeled apple slices for the sensory attributes hardness, crispness, crunchiness, juiciness, apple flavor, sweet taste, and sour taste. Each treatment was replicated 10 times and was tested over $5 \mathrm{~d}$, two replicates each day. The treatments were presented to the judges in a completely randomized order. Each judge received an apple slice from the same apple; hence, the sample size was an eighth of an apple. We did not distinguish between the shaded and exposed sides of the outer canopy fruit. Each sample was coded with a three-digit random code and samples were presented on petri dishes. Judges were seated in individual booths with computers at a room temperature of $21{ }^{\circ} \mathrm{C}$. Each computer was fitted with the computer program Compusense five ${ }^{\circledR}$ (Compusense, Guelph, Canada) for data entry. The judges used distilled water and unsalted fat-free biscuits to refresh their palate.

Consumer preference studies. In 2010, 'Starking' and 'Golden Delicious' were tasted by 99 consumers and 'Granny Smith' was tasted by 97 consumers. In 2011, 'Starking' and 'Golden Delicious' were tasted by 94 and 'Granny Smith' by 100 consumers. Consumers were presented with each cultivar separately; hence, they assessed the inside and outside treatments for each cultivar without influence of perhaps stronger or differing flavor attributes of the other cultivars. In these analyses, the hedonic response was tested and consumers were presented with a questionnaire divided into three sections. The first section consisted of the eating quality assessment of the apples samples presented to the consumer, the second section was a visual assessment of apple appearance, primarily color, and the third section consisted of a general enquiry of the apple quality preferences and general sociodemographic information of the consumers. The data for the third section of the questionnaire are not presented in this article.

Apples were peeled, slices were coded with a three-digit random code, and presented on open petri dishes in random order. We did not distinguish between the shaded and exposed sides of the outer canopy fruit. In the eating quality assessment, consumers were 
asked to taste the fruit and to indicate, using a 9-point hedonic scale, which term best described how they perceived the product that they have tasted. The 9-point hedonic scale ranges from $1=$ dislike extremely to $5=$ neither like nor dislike to $9=$ like extremely (Lawless and Heymann, 2010). Distilled water and unsalted, fat-free biscuits were available for consumers to clean their palate between samples. A room temperature of $21^{\circ} \mathrm{C}$ was maintained throughout the tasting.

Photographs of whole apple fruit were presented to the consumers for assessment (Fig. 1). Three photographs of each treatment, presented in a randomized fashion, were used in the study. Consumers were presented with pictures of inside (without blush) and outside (with blush) whole apple fruit of the cultivars they had been presented with for the eating quality assessment. They assessed the pictures using the 9-point hedonic scale. These assessments were used to determine the degree of liking of appearance.

Statistical analysis. The physicochemical and preference data were analyzed separately for each cultivar by analysis of variance (ANOVA) using SAS General Linear Models (SAS Version 9.2; SAS Institute, Cary, NC). A Levene's test for homogeneity of variance was performed to test if the year variability in the observations were comparable in magnitude (Levene, 1960). A weighted ANOVA was performed for the variables showing heterogeneity of variances in years. The reciprocal of the mean square error for each year for the variables showing heterogeneity of variances in years was used as a weight. The Shapiro-Wilk test was performed to test for non-normality (Shapiro and Wilk, 1965). Student's $t$-least significant difference was calculated at the $5 \%$ significance level to compare treatment means. Principal component analysis (PCA) was carried out to identify variables that associate with certain treatments and discriminant analysis was used to classify treatments similar to each other (Rencher, 2002).

\section{Results}

Light and temperature. Average light readings on 3 Mar. 2010 for outer canopy 'Starking' fruit were almost 30 times higher than for fruit in the innermost portion of the canopy (Fig. 2). The average peel temperature of outer canopy 'Starking' fruit was $\approx 10{ }^{\circ} \mathrm{C}$ higher than inner canopy fruit and $9{ }^{\circ} \mathrm{C}$ higher than the average ambient air temperature (Fig. 3). We collected these data on 'Starking' only with the intention to illustrate typical microclimatic differences between the inner and outer canopies of large apple trees.

Fruit color and pigment concentrations. Outer canopy fruit were redder and contained more anthocyanins (assessed in 2010 only) than inner canopy fruit (Tables 1 and 2; Fig. 1). 'Starking' fruit were redder in 2011 than in 2010 (Table 1). Outer canopy 'Golden Delicious' and 'Granny Smith' fruit were redder than inner canopy fruit in both years, but the difference was more pronounced in 2010. Inner canopy 'Granny Smith' fruit were greener in 2010 than in 2011. Carotenoid concentrations in outer canopy fruit were significantly higher in 'Starking' (Table 2). The chlorophyll concentration was significantly lower and the ground color significantly more yellow in outer canopy 'Golden Delicious' and 'Granny Smith' fruit (Table 2).

Physiochemical measurements. In 'Starking', no differences were observed in firmness between inner and outer canopy fruit for both years (Table 3 ). TSS values were $\approx 2$ ${ }^{\circ}$ Brix higher in outer canopy fruit in both years. Higher TSS values were observed in 2010 compared with 2011 with a difference of nearly $2{ }^{\circ}$ Brix between the years. TA was significantly higher for inside canopy fruit of 2010, whereas no significant differences were observed in 2011. The much higher TSS and much lower TA values resulted in a high TSS:TA value in outer canopy 'Starking' of 2010 compared with all the other values. TSS:TA ratio in both years was higher for outside canopy fruit. The TSS of outer canopy fruit in 2011 was statistically not different from that of the inner canopy fruit in 2010 . This explains the year and treatment interaction observed.

'Golden Delicious' from 2011 was firmer than 2010 with outer canopy fruit being slightly firmer than inner canopy fruit in both years (Table 3). Outer canopy fruit were nearly $2{ }^{\circ}$ Brix higher in TSS, whereas TSS was $\approx 3{ }^{\circ}$ Brix higher in 2010 compared with

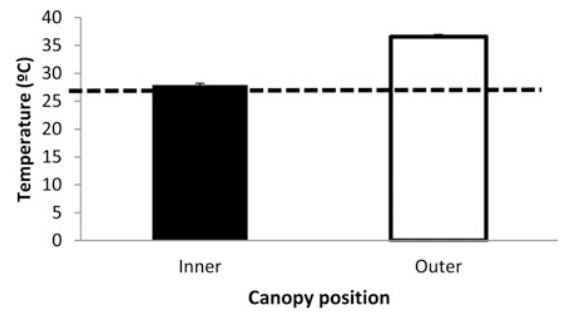

Fig. 3. Average peel temperatures of fruit from the inner and outer canopy positions from $0900 \mathrm{HR}$ to $1700 \mathrm{HR}$ measured in a 'Starking' orchard on 1 Mar. 2010, a cloudless day. Values are means \pm SE $(\mathrm{n}=10)$. The average ambient temperature of $27^{\circ} \mathrm{C}$ is indicated with a line.

Table 1 . The effect of canopy position (inner canopy versus outer canopy fruit) on hue angles of outer and inner canopy 'Starking', 'Golden Delicious', and 'Granny Smith' fruit harvested in 2010 and 2011 at Vastrap Farm in Ceres, Western Cape, South Africa. ${ }^{\text {z }}$

\begin{tabular}{lcccr}
\hline Yr & Canopy position & Starking & Golden Delicious & Granny Smith \\
\hline 2010 & Inner & $64.7 \mathrm{a}^{\mathrm{y}}$ & $112.3 \mathrm{a}$ & $118.3 \mathrm{a}$ \\
& Outer & $35.4 \mathrm{~b}$ & $81.3 \mathrm{c}$ & $81.0 \mathrm{~d}$ \\
2011 & Inner & $58.1 \mathrm{a}$ & $112.2 \mathrm{a}$ & $114.1 \mathrm{~b}$ \\
& Outer & $21.3 \mathrm{~b}$ & $94.9 \mathrm{~b}$ & $89.8 \mathrm{c}$ \\
$P$ value & & & & \\
Year (Y) & & 0.0003 & $<0.0001$ & 0.0525 \\
Position (P) & & $<0.0001$ & $<0.0001$ & $<0.0001$ \\
Y*P & & 0.1292 & $<0.0001$ & $<0.0001$ \\
\hline
\end{tabular}

${ }^{\mathrm{z}}$ Measured within 1 month and stored at $-0.5^{\circ} \mathrm{C}$.

${ }^{y}$ Means with different letters differ significantly at $P<0.05$ in the column.

Table 2. The effect of canopy position (inside versus outside canopy) on the pigment concentrations in the peel of 'Granny Smith', 'Golden Delicious', and 'Starking' apples harvested at Vastrap Farm in Ceres, Western Cape, South Africa.

\begin{tabular}{lccc}
\hline & $\begin{array}{c}\text { Anthocyanin } \\
\left(\mu \mathrm{g} \cdot \mathrm{g}^{-1} \mathrm{FW}\right)\end{array}$ & $\begin{array}{c}\text { Carotenoid } \\
\left(\mu \mathrm{g} \cdot \mathrm{g}^{-1} \mathrm{FW}\right)\end{array}$ & $\begin{array}{r}\text { Chlorophyll } \\
\left(\mu \mathrm{g} \cdot \mathrm{g}^{-1} \mathrm{FW}\right)\end{array}$ \\
\hline Granny Smith & $1.6 \mathrm{~b}^{\mathrm{z}}$ & $35.4 \mathrm{NS}$ & $153.6 \mathrm{a}$ \\
Inner canopy & $98.9 \mathrm{a}$ & 34.4 & $111.3 \mathrm{~b}$ \\
$\quad$ Outer canopy & $<0.0001$ & 0.5583 & $<0.0001$ \\
$P$ value & $251.2 \mathrm{~b}$ & $22.2 \mathrm{~b}$ & $41.6 \mathrm{NS}$ \\
Starking & $735.6 \mathrm{a}$ & $32.9 \mathrm{a}$ & 49.8 \\
Inner canopy & $<0.0001$ & $<0.0001$ & 0.1293 \\
Outer canopy & & & $75.3 \mathrm{a}$ \\
$P$ value & $0.0 \mathrm{~b}$ & $26.4 \mathrm{NS}$ & $62.5 \mathrm{~b}$ \\
Golden Delicious & $49.7 \mathrm{a}$ & 30.1 & 0.0139 \\
Inner canopy & $<0.0001$ & 0.0712 & \\
Outer canopy & & & \\
$P$ value & & & \\
\hline
\end{tabular}

${ }^{\mathrm{z}}$ Means with different letters differ significantly at $P<0.05$ in the column.

Ns Nonsignificant.

$\mathrm{FW}=$ fresh weight. 
Table 3. The effect of inner versus outer canopy position on firmness (N), titratable acidity (TA, $\%$ malic acid), total soluble solids (TSS, ${ }^{\circ}$ Brix), and TSS:TA ratio for 'Starking', 'Golden Delicious', and 'Granny Smith' harvested in 2010 and 2011 at Vastrap Farm, Ceres, South Africa, within 1 month at $-0.5^{\circ} \mathrm{C}$.

\begin{tabular}{|c|c|c|c|c|c|c|c|c|c|c|c|c|}
\hline & \multicolumn{4}{|c|}{ Starking } & \multicolumn{4}{|c|}{ Golden Delicious } & \multicolumn{4}{|c|}{ Granny Smith } \\
\hline & Firmness & TSS & TA & TSS:TA & Firmness & TSS & TA & TSS:TA & Firmness & TSS & TA & TSS:TA \\
\hline Inner & $82.3 \mathrm{NS}$ & $12.8 \mathrm{~b}^{\mathrm{z}}$ & $0.27 \mathrm{a}$ & $47.7 \mathrm{~b}$ & $61.7 \mathrm{~d}$ & $14.2 \mathrm{~b}$ & $0.43 \mathrm{a}$ & $33.0 \mathrm{~b}$ & $76.4 \mathrm{c}$ & $11.3 \mathrm{~b}$ & $0.85 \mathrm{a}$ & $13.3 \mathrm{c}$ \\
\hline Inner & 82.3 & $10.4 \mathrm{c}$ & $0.28 \mathrm{a}$ & $36.5 \mathrm{c}$ & $73.5 \mathrm{~b}$ & $11.2 \mathrm{~d}$ & $0.41 \mathrm{a}$ & $26.9 \mathrm{c}$ & $79.4 \mathrm{~b}$ & $11.5 \mathrm{~b}$ & $0.67 \mathrm{c}$ & $17.0 \mathrm{~b}$ \\
\hline Outer & 82.3 & $13.0 \mathrm{~b}$ & $0.27 \mathrm{a}$ & $48.4 \mathrm{~b}$ & $79.4 \mathrm{a}$ & $13.4 \mathrm{c}$ & $0.42 \mathrm{a}$ & $31.8 \mathrm{~b}$ & $86.2 \mathrm{a}$ & $12.9 \mathrm{a}$ & $0.71 \mathrm{bc}$ & $18.3 \mathrm{a}$ \\
\hline \multicolumn{13}{|l|}{$P$ value } \\
\hline $\mathrm{Y} * \mathrm{P}$ & 0.7748 & 0.0076 & 0.0009 & 0.0078 & 0.0486 & 0.2701 & 0.0079 & 0.1769 & 0.4726 & 0.0682 & 0.0017 & 0.0004 \\
\hline
\end{tabular}

${ }^{\mathrm{z}}$ Means with different letters differ significantly at $P<0.05$ in the column.

Ns Nonsignificant.

2011. TA was significantly higher for inner canopy fruit of 2010, whereas no difference was observed in 2011. Outer canopy fruit were higher in TSS:TA ratio and the ratio was higher in 2010 than in 2011.

'Granny Smith' outer canopy fruit was firmer in both years and firmness was lower in 2010 than in 2011 (Table 3). TSS was $\approx 2$ ${ }^{\circ}$ Brix and $1.5{ }^{\circ}$ Brix higher for outer canopy fruit in 2010 and 2011, respectively. There were no significant differences observed between the years. TA in the second season was slightly lower compared with the first season. There was no significant positional difference for TA in 2011, whereas inner canopy fruit had a higher TA in 2010. The TSS:TA ratio was significantly higher for outside canopy fruit in both years.

The DMC was higher for outer canopy fruit in all three cultivars (Table 4). DMC in 'Starking' and 'Granny Smith' was higher in 2011, whereas DMC in 'Golden Delicious' was higher in 2010.

Cropload of the orchards was comparable between seasons and no canopy position effect on fruit size was found (data not presented).

Total reducing sugars, ascorbic acid, total phenolics, and antioxidant capacity. Total sugar concentrations were significantly higher in outer canopy fruit in all three cultivars (Table 5). Apple peel in all three cultivars had higher ascorbic acid concentrations and total phenolics as well as higher antioxidant capacities than apple flesh (Tables 5 and 6). In both flesh and peel samples of all three cultivars, outer canopy fruit had a significantly higher total phenolics concentration and antioxidant capacity than inner canopy fruit. Ascorbic acid concentrations in the peel of all three cultivars were significantly higher in outer canopy fruit. Although only significant in 'Granny Smith', there was a trend of higher ascorbic acid concentrations in the flesh of outer canopy fruit (Table 5).

Sensory attributes. In 'Starking', all sensory attributes were higher in 2011 than in 2010 (Table 7). Outer canopy 'Starking' had higher apple flavor and sweet taste, whereas inner canopy fruit were higher in sourness. 'Golden Delicious' fruit were higher in apple flavor and sourness in 2011 than in 2010, but sweet taste did not differ between the seasons (Table 7). Outer canopy fruit were sweeter

Table 4 . The effect of canopy position (inner canopy versus outer canopy fruit) on the dry matter concentration: DMC (\%) of 'Golden Delicious', 'Granny Smith', and 'Starking' harvested in 2010 and 2011 at Vastrap Farm in Ceres, Western Cape, South Africa, measured within 1 month and stored at $-0.5^{\circ} \mathrm{C}$.

\begin{tabular}{lccr}
\hline Treatment & Golden Delicious & Granny Smith & Starking \\
\hline Year & $15.4 \mathrm{a}^{\mathrm{z}}$ & $11.5 \mathrm{~b}$ & $13.3 \mathrm{~b}$ \\
2010 & $14.3 \mathrm{~b}$ & $14.6 \mathrm{a}$ & $15.0 \mathrm{a}$ \\
2011 & & & \\
Position & $13.9 \mathrm{~b}$ & $12.3 \mathrm{~b}$ & $13.1 \mathrm{~b}$ \\
$\quad$ Inside & $15.8 \mathrm{a}$ & $14.1 \mathrm{a}$ & $15.3 \mathrm{a}$ \\
Outside & & $<0.0001$ & \\
$P$ value & 0.0300 & $<0.0001$ & $<0.0001$ \\
Year (Y) & 0.0004 & 0.3837 & 0.2236 \\
Position (P) & 0.7370 & \\
Y*P &
\end{tabular}

${ }^{\mathrm{z}}$ Means with different letters differ significantly at $P<0.05$ in the column.

Table 5. The effect of canopy position (inside versus outside canopy) on antioxidants, ascorbic acid, and phenolics in the flesh of 'Starking', 'Golden Delicious', and 'Granny Smith' apples harvested in 2010 at Vastrap Farm, Ceres, South Africa.

\begin{tabular}{lcccc}
\hline & $\begin{array}{c}\text { Total sugars } \\
\left(\mathrm{mg} \cdot \mathrm{g}^{-1} \mathrm{FW}\right)\end{array}$ & $\begin{array}{c}\text { Total phenolics } \\
(\mathrm{mg} / 100 \mathrm{~g} \mathrm{FW})\end{array}$ & $\begin{array}{c}\text { Total ascorbic acid } \\
(\mathrm{mg} / 100 \mathrm{~g} \mathrm{FW})\end{array}$ & $\begin{array}{c}\text { Antioxidant capacity } \\
(\mathrm{mg} \text { TEAC/g FW })\end{array}$ \\
\hline Starking & $113.3 \mathrm{~b}$ & $24.2 \mathrm{~b}$ & $19.3 \mathrm{NS}$ & $1.66 \mathrm{~b}$ \\
$\quad$ Inside canopy & $128.2 \mathrm{a}$ & $27.4 \mathrm{a}$ & 21.6 & $2.25 \mathrm{a}$ \\
Outside canopy & 0.0005 & 0.0064 & 0.5413 & 0.0007 \\
$P$ value & & & & $1.76 \mathrm{~b}$ \\
Golden Delicious & $125.1 \mathrm{~b}$ & $16.8 \mathrm{~b}$ & $20.6 \mathrm{NS}$ & $2.25 \mathrm{a}$ \\
Inside canopy & $148.3 \mathrm{a}$ & $22.8 \mathrm{a}$ & 22.6 & 0.0011 \\
Outside canopy & $<0.0001$ & $<0.0001$ & 0.1265 & $1.65 \mathrm{~b}$ \\
$P$ value & & & $19.6 \mathrm{~b}$ & $2.83 \mathrm{a}$ \\
Granny Smith & $97.8 \mathrm{~b}$ & $18.2 \mathrm{~b}$ & $29.3 \mathrm{a}$ & $<0.0001$ \\
Inside canopy & $118.3 \mathrm{a}$ & $23.8 \mathrm{a}$ & $<0.0001$ & \\
Outside canopy & $<0.0001$ & $<0.0001$ &
\end{tabular}

${ }^{\mathrm{z}}$ Means with different letters differ significantly at $P<0.05$ in the column.

Ns Nonsignificant.

$\mathrm{FW}=$ fresh weight; TEAC $=$ Trolox equivalent antioxidant capacity.

and higher in apple flavor than inner canopy fruit, whereas inner canopy fruit were higher in sourness. The apple flavor and sweet taste of 'Granny Smith' fruit were perceived to be higher in 2011, whereas sourness was higher in 2010 (Table 7). There were no significant differences in apple flavor between inner and outer canopy fruit, but outer canopy fruit were higher in sweet taste and lower in sourness.

Consumer preference. Consumers preferred the eating quality of outer canopy fruit over inner canopy fruit in all three cultivars (Table 8). The eating quality of 'Golden Delicious' and 'Starking' in 2010 was preferred over that of 2011, whereas no difference in preference was observed between years for
'Granny Smith'. Consumers preferred the appearance of inner canopy 'Golden Delicious' and 'Granny Smith' apples and outer canopy 'Starking' apples, but no differences were observed between the years.

The PCA for 'Starking', 'Golden Delicious', and 'Granny Smith' explained $\approx 88 \%$, $95 \%$, and $96 \%$, respectively, of the variation when considering the first two factors or principle components (Fig. 4). In all three cultivars, differences resulting from season were clearly separated along the horizontal axis (F1) explaining the greater part of the variation $(\approx 60 \%)$. The variation brought about by the canopy position occurred along the vertical axis (F2) explaining $\approx 30 \%$ of the variation. 
Table 6. The effect of canopy position (inner versus outer canopy) on antioxidants, ascorbic acid, and phenolics in the peel of 'Starking', 'Golden Delicious', and 'Granny Smith' apples harvested in 2010 at Vastrap Farm, Ceres, South Africa. ${ }^{\mathrm{z}}$

\begin{tabular}{lccc}
\hline & $\begin{array}{c}\text { Total ascorbic acid } \\
(\mathrm{mg} / 100 \mathrm{~g} \mathrm{FW})\end{array}$ & $\begin{array}{c}\text { Total phenolics } \\
(\mathrm{mg} / 100 \mathrm{~g} \mathrm{FW})\end{array}$ & $\begin{array}{c}\text { Antioxidant capacity } \\
(\mathrm{mg} \text { TEAC/g FW })\end{array}$ \\
\hline Starking & $120 \mathrm{~b}$ & $204 \mathrm{~b}$ & $18.5 \mathrm{~b}$ \\
Inside canopy & $167 \mathrm{a}$ & $353 \mathrm{a}$ & $21.6 \mathrm{a}$ \\
Outside canopy & $<0.0001$ & $<0.0001$ & $<0.0001$ \\
$P$ value & $80 \mathrm{~b}$ & $224 \mathrm{~b}$ & $13.2 \mathrm{~b}$ \\
Golden Delicious & $610 \mathrm{a}$ & $310 \mathrm{a}$ & $21.4 \mathrm{a}$ \\
Inside canopy & $<0.0001$ & $<0.0001$ & $<0.0001$ \\
Outside canopy & & & $15.8 \mathrm{~b}$ \\
$P$ value & $289 \mathrm{~b}^{\mathrm{y}}$ & $128 \mathrm{~b}$ & $19.2 \mathrm{a}$ \\
Granny Smith & $991 \mathrm{a}$ & $437 \mathrm{a}$ & $<0.0001$ \\
Inside canopy & $<0.0001$ & $<0.0001$ & \\
Outside canopy & & & \\
$P$ value & & & \\
\hline
\end{tabular}

${ }^{z}$ Peel from the exposed and shaded sides of outer canopy fruit was pooled together for the assessment. ${ }^{y}$ Means with different letters differ significantly at $P<0.05$ in the column.

$\mathrm{FW}=$ fresh weight; TEAC $=$ Trolox equivalent antioxidant capacity.

Table 7. The effect of inner versus outer canopy position on sensory characteristics of 'Starking', 'Golden Delicious', and 'Granny Smith' apples harvested at Vastrap Farm, Ceres, South Africa, measured on a $100-\mathrm{mm}$ unstructured line scale ranging from 0 to 100 according to the perceived strength of the attributes during descriptive sensory analysis in 2010 and 2011.

\begin{tabular}{|c|c|c|c|c|c|c|c|c|c|}
\hline & \multicolumn{3}{|c|}{ Starking } & \multicolumn{3}{|c|}{ Golden Delicious } & \multicolumn{3}{|c|}{ Granny Smith } \\
\hline & $\begin{array}{l}\text { Apple } \\
\text { flavor }\end{array}$ & $\begin{array}{c}\text { Sweet } \\
\text { taste }\end{array}$ & $\begin{array}{l}\text { Sour } \\
\text { taste }\end{array}$ & $\begin{array}{l}\text { Apple } \\
\text { flavor }\end{array}$ & $\begin{array}{l}\text { Sweet } \\
\text { taste }\end{array}$ & $\begin{array}{l}\text { Sour } \\
\text { taste }\end{array}$ & $\begin{array}{l}\text { Apple } \\
\text { flavor }\end{array}$ & $\begin{array}{l}\text { Sweet } \\
\text { taste }\end{array}$ & $\begin{array}{l}\text { Sour } \\
\text { taste }\end{array}$ \\
\hline \multicolumn{10}{|l|}{ Year } \\
\hline 2010 & $34 b^{z}$ & $44 \mathrm{~b}$ & $26 \mathrm{~b}$ & $49 b^{z}$ & $52 \mathrm{NS}$ & $38 \mathrm{~b}$ & $49 b^{z}$ & $35 \mathrm{~b}$ & $73 \mathrm{a}$ \\
\hline 2011 & $52 \mathrm{a}$ & $57 \mathrm{a}$ & $33 \mathrm{a}$ & $58 \mathrm{a}$ & 54 & $43 \mathrm{a}$ & $59 \mathrm{a}$ & $56 \mathrm{a}$ & $56 \mathrm{~b}$ \\
\hline \multicolumn{10}{|l|}{ Position } \\
\hline Inside & $39 \mathrm{~b}$ & $42 \mathrm{~b}$ & $29 \mathrm{a}$ & $52 \mathrm{~b}$ & $50 \mathrm{~b}$ & $43 \mathrm{a}$ & $54 \mathrm{NS}$ & $44 \mathrm{~b}$ & $67 \mathrm{a}$ \\
\hline Outside & $49 \mathrm{a}$ & $60 \mathrm{a}$ & $25 \mathrm{~b}$ & $56 \mathrm{a}$ & $57 \mathrm{a}$ & $38 \mathrm{~b}$ & 55 & $48 \mathrm{a}$ & $61 \mathrm{~b}$ \\
\hline \multicolumn{10}{|l|}{$P$ value } \\
\hline Year (Y) & $<0.0001$ & $<0.0001$ & $<0.0001$ & $<0.0001$ & 0.1444 & 0.0025 & $<0.0001$ & $<0.0001$ & $<0.0001$ \\
\hline Position $(\mathrm{P})$ & $<0.0001$ & $<0.0001$ & 0.0012 & $<0.0001$ & $<0.0001$ & 0.0100 & 0.0785 & 0.0058 & 0.0077 \\
\hline $\mathrm{Y}^{*} \mathrm{P}$ & 0.2183 & 0.1081 & 0.2159 & 0.0504 & 0.6987 & 0.7212 & 0.2713 & 0.1864 & 0.5887 \\
\hline
\end{tabular}

${ }^{\mathrm{z}}$ Treatments with different letters differ significant at $P<0.05$.

Ns Nonsignificant.

Table 8. The effect of canopy position (inner canopy versus outer canopy fruit) on the eating quality and appearance liking of Stellenbosch consumers for 'Golden Delicious', 'Starking', and 'Granny Smith' apples harvested at Vastrap Farm in Ceres, Western Cape, South Africa, in 2010 and 2011 . $^{\text {. }}$

\begin{tabular}{|c|c|c|c|c|c|c|}
\hline & \multicolumn{2}{|c|}{ Golden Delicious } & \multicolumn{2}{|c|}{ Granny Smith } & \multicolumn{2}{|c|}{ Starking } \\
\hline & $\begin{array}{l}\text { Eating } \\
\text { quality }\end{array}$ & Appearance & $\begin{array}{l}\text { Eating } \\
\text { quality }\end{array}$ & Appearance & $\begin{array}{l}\text { Eating } \\
\text { quality }\end{array}$ & Appearance \\
\hline \multicolumn{7}{|l|}{ Year } \\
\hline 2010 & $6.8 \mathrm{a}^{\mathrm{y}}$ & $6.5 \mathrm{NS}$ & $6.5 \mathrm{NS}$ & $6.5 \mathrm{NS}$ & $7.1 \mathrm{a}$ & $6.4 \mathrm{NS}$ \\
\hline 2011 & $6.4 \mathrm{~b}$ & 6.6 & 6.5 & 6.6 & $5.9 \mathrm{~b}$ & 6.9 \\
\hline \multicolumn{7}{|l|}{ Position } \\
\hline Inside & $6.4 \mathrm{~b}$ & $7.1 \mathrm{a}$ & $6.4 \mathrm{~b}$ & $6.9 \mathrm{a}$ & $6.1 \mathrm{~b}$ & $5.9 \mathrm{~b}$ \\
\hline Outside & $6.8 \mathrm{a}$ & $6.0 \mathrm{~b}$ & $6.7 \mathrm{a}$ & $6.2 \mathrm{~b}$ & $7.0 \mathrm{a}$ & $7.4 \mathrm{a}$ \\
\hline \multicolumn{7}{|l|}{$P$ value } \\
\hline Year $(\mathrm{Y})$ & 0.0087 & 0.2475 & 0.8425 & 0.6736 & $<0.0001$ & 0.0653 \\
\hline Position (P) & 0.0008 & $<0.0001$ & 0.0133 & $<0.0001$ & $<0.0001$ & $<0.0001$ \\
\hline $\mathrm{Y} * \mathrm{P}$ & 0.3277 & 0.5078 & 0.1049 & 0.4797 & 0.7275 & 0.0980 \\
\hline
\end{tabular}

${ }^{\mathrm{z}}$ Liking was scored on a 9-point hedonic scale where 1 and 9 indicate extreme dislike and liking, respectively, and 5 represents neither dislike nor liking.

y Treatments with different letters differ significant at $P<0.05$.

Ns Nonsignificant.

\section{Discussion}

Chemical composition. The position of apple fruit in the canopy influences their appearance and chemical composition. Pigment, phenolic, ascorbic acid, and carbohydrate levels as well as the antioxidant capacity of fruit were generally higher in outer canopy fruit and seem to relate to microclimatic differences in irradiance
Improved light exposure and higher temperatures lead to higher sugar levels and TSS in apples (Nilsson and Gustavsson, 2007; Solomakhin and Blanke, 2010) and peaches (Lewallen and Marini, 2003). Outer canopy fruit of all three cultivars had higher DMCs in agreement with previous findings (Scurlock et al., 1985). DMC is an important holistic measurement of fruit quality because it is an indicator of physiological and metabolic processes that contribute to the final composition of the fruit (Harker et al., 2009). No differences were observed in fruit size between inner and outer canopy fruit (data not presented). A linear relationship between fruit size and light exposure has been established (Robinson et al., 1983). The lack of a positional effect on fruit size in our study may be the result of the selective removal of small fruit during hand thinning.

The higher levels of anthocyanins, ascorbic acid, phenolic compounds as well as the higher antioxidant capacity of sun-exposed apple peel can be explained from a photoprotective perspective. These compounds play a photoprotective role in apple peel and light is an important regulatory factor in their synthesis (Demmig-Adams and Adams, 1992; Ma and Cheng, 2003; Takos et al., 2006). The combination of high light, including high ultraviolet radiation, and high temperatures in the outer canopy causes a significant amount of stress to plants and induces the formation of harmful reactive oxygen species (Foyer et al., 1994). Apple fruit exposed to such environments are prone to photodamage disorders such as sunburn (Schrader et al., 2003) and photobleaching of chlorophyll (Olszowka et al., 2003).

Apple flesh from outer canopy fruit was also higher in antioxidant capacity and phenolic compounds. Ascorbic acid was only higher in the flesh of outer canopy 'Granny Smith' fruit. Drogoudi and Pantelidis (2011) found higher total phenolic concentrations and higher total antioxidant capacities in the flesh of outer canopy fruit in two of the four apples cultivars included in their study. However, postharvest irradiation with ultraviolet and visible light increased phenolic levels and antioxidant capacity in the peel, but not in the flesh of 'Aroma' apple (Hagen et al., 2007). Because ascorbic acid, phenolics, and antioxidants have been found to provide protection against chronic diseases (Dragsted et al., 1993; Lila, 2004; Moyer et al., 2002), outer canopy fruit may be perceived as a healthier product.

The response of the fruit to the canopy microclimatic environment is subject to the general environmental conditions in that season. Nilsson and Gustavsson (2007) found that differences in TSS between inner and outer canopy fruit were reduced and the TA was increased in the second year of their study as a result of higher temperatures compared with the first season. Similarly, seasonal differences were observed between 2009-10 and 2010-11 fruit in all three cultivars. PCA biplots (Fig. 4) illustrate that the variation between the seasons (along the horizontal 

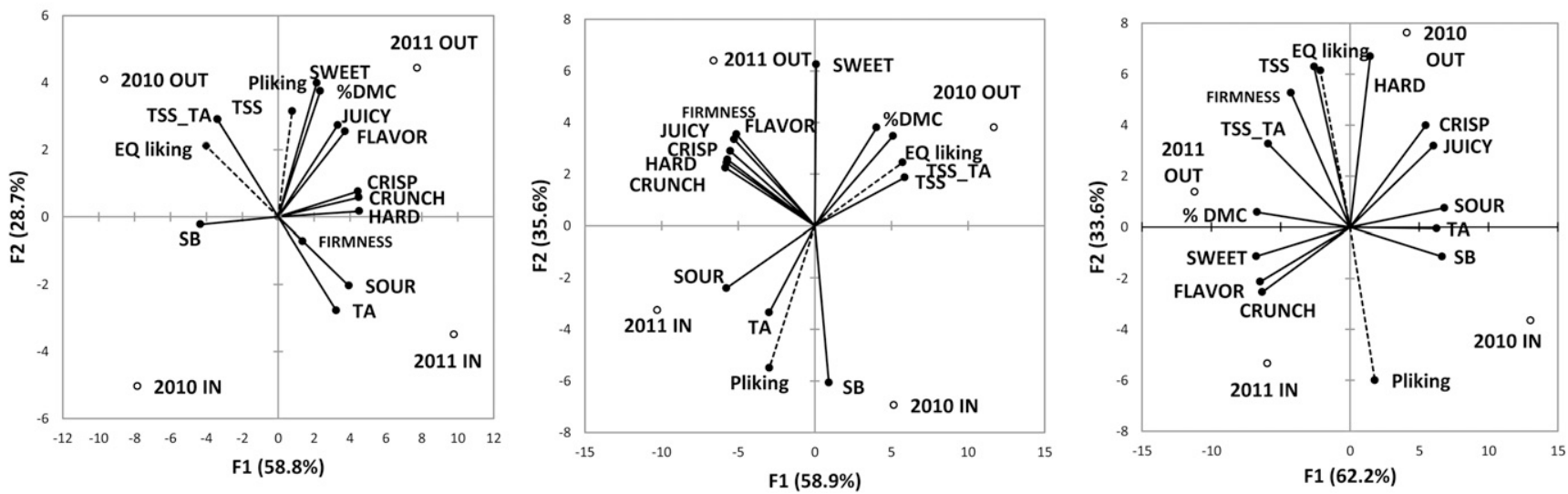

Fig. 4. Principal component analysis (PCA) biplots indicating the position of consumer preference for eating quality (EQ liking) and photograph liking (Pliking) (dashed black lines) in relation to the sensory attributes (solid black lines) and chemical composition (solid black lines) of inside (IN) and outside (OUT) canopy 'Starking', 'Granny Smith', and 'Golden Delicious' apple fruit harvested in the years 2010 and 2011 where SB = starch breakdown, DMC = dry matter concentration $(\%)$.

axis) accounted for a greater percentage $(\approx 60 \%)$ of total variance in consumer preference for eating quality and appearance than the variation found between the inner and outer canopies $(\approx 30 \%)$. This shows that the macroclimate had an overbearing effect on fruit quality parameters compared with canopy microclimatic conditions. In 'Starking', the seasonal differences observed could be the result of the 3-week difference in harvesting date between the seasons, but 'Golden Delicious' and 'Granny Smith' were harvested within the same calendar week in both seasons.

Eating quality and consumer preference. Consumer preference is influenced by a number of factors including color (Thybo et al., 2004), flavor, texture, and taste (DaillantSpinnler et al., 1996; Harker, 2001) as well as non-quality-related factors such as familiarity and previous exposure (Pollard et al., 2002). The generally higher consumer eating quality liking for outer canopy fruit seems to relate to their higher TSS, TSS:TA ratio, and $\mathrm{DMC}$ as well as the enhanced apple flavor in outer canopy 'Starking' and 'Golden Delicious'. This is in agreement with previous studies that found strong associations of eating quality liking with apple flavor, TSS, TSS:TA ratio, sweetness, firmness, and DMC (Harker, 2001; Jackson, 2003; Palmer et al., 2010). 'Royal Gala' apples that were higher in DMC were preferred by consumers and were also higher in TSS, TA, and firmness (Palmer et al., 2010). DMC correlated ( $r=$ 0.692 ) with eating quality liking. Eating quality liking also correlated positively with apple flavor, sweetness, and TSS ( $r$ of 0.74 , 0.67 and 0.72 , respectively).

Appearance liking. For 'Starking', the appearance of outer canopy fruit was preferred, most likely as a result of the redder color of these fruit. 'Starking' fruit with insufficient red color are downgraded and consumers are likely to associate redder color with increased quality. In nature, fruit color has important visual functions in attracting consumers and signaling fruit maturity, nutrition, and health benefits as well as eating quality (Steyn, 2012). Red color increases sweetness perception as has been observed in various beverages including aqueous solutions (Johnson and Clydesdale, 1982), strawberryflavored beverages (Johnson et al., 1983), and cherry-flavored beverages (Johnson et al., 1982). Daillant-Spinnler et al. (1996) found that red cultivars were associated with sweet sensory descriptors and green cultivars were associated with sour or acidic taste descriptors. The redness and extent of red color seem to be reliable indicators of eating quality in 'Starking'. However, there are instances in which red color may not be a good indicator of fruit internal quality (Steyn, 2012, and references therein). For example, consumers find it difficult to infer fruit maturity in highly pigmented, full red cultivars where the red color masks changes in background color. Fruit of these cultivars may differ considerably in maturity and internal quality despite having similar color.

Consumers preferred the appearance of the green inner canopy 'Golden Delicious' and 'Granny Smith' fruit to the blushed outer canopy fruit, opposite of their preference for the eating quality of the outer canopy fruit. Consumers did not know which treatments they tasted as peeled fruit were used in the assessments and eating quality and photograph assessments were carried out independently. Appearance provides the first impression of the fruit that will either attract or repel the consumer (Kays, 1998). In South Africa and most other countries, 'Granny Smith' and 'Golden Delicious' are traditionally marketed without a red blush. Fruit with a red blush are mostly downgraded for juicing or are sold at a lower price. Therefore, consumers are generally not familiar with the blushed form of these cultivars or may associate them with lower quality. The basis for culling these fruit is purely aesthetic, although there is a small consumer segment that prefers sour and dislikes sweet apples (Van der Merwe, 2013) and who might prefer both the overall eating quality and appearance of inner canopy 'Granny Smith' fruit. 'Granny Smith' is one of the most familiar apple cultivars and is distinguished from other cultivars by its tartness (Warrington, 1994); therefore, consumers are most probably drawn to this cultivar for this characteristic. It is possible that a fully green-colored 'Granny Smith' best signals to the consumer the chemical and sensory qualities they are looking for in the fruit. This would, however, not apply to 'Golden Delicious', which is considered a sweet cultivar and for which consumer preference for taste can be expected to increase with increasing sweetness.

The consumers participating in our study probably found the blushed 'Granny Smith' and 'Golden Delicious' to be inappropriately colored based on their expectations and previous experience. Various studies have investigated the effect of color and taste expectation matching on consumer preference. When consumers were asked to taste flavored drinks, appropriate coloring (limeflavored colored green) resulted in higher correct identification of flavor, whereas inappropriate coloring, e.g., lime flavor drink colored orange, resulted in a lower percentage of correct responses (Zampini et al., 2007). In a study aimed at correlating taste and visual assessments of apples, it was found that 'Red Delicious' apples were rejected on appearance based on a bad reputation that they have little overall taste. However, on taste assessments of these fruit, consumers liked the taste of the apples (Schechter, 2010). Consumers liked the appearance of 'Jonagold' apples but did not like their taste. This may be because 'Jonagold', a firm and slightly tart apple, is mistaken for a sweet apple as a result of its red appearance (Schechter, 2010). In a Danish study with children, it was found that those who reported that they like red apples indeed had high preference for the taste of the red apples, and those who reported liking for green apples had a high preference for the taste of green apples, thus showing consistency 
(Thybo et al., 2004). This illustrates that even at young ages, people have learned associations and expectations of fruit based on their color.

Conclusions. This research has revealed that inner and outer canopy fruit differ in their appearance and chemical and sensory characteristics and these differences, although small in some cases, affect consumer liking. Outer canopy fruit generally had the qualities that gave them good eating quality and higher consumer preference. However, orchard systems that maximize light penetration into the canopy may reduce the differences observed between inner and outer canopy fruit.

Grading of 'Starking' and most probably also other fully red and bicolored cultivars based on the extent of red color development seems justified from an eating quality perspective. In contrast, red-blushed 'Golden Delicious' and 'Granny Smith' fruit are downgraded for purely aesthetic reasons because these fruit are of better eating quality than the green inner canopy fruit. The lower liking for blushed outer canopy 'Granny Smith' and 'Golden Delicious' fruit may be the result of the unfamiliarity of consumers with these fruit. Although the green color of 'Granny Smith' probably associates with the taste characteristics desired by the consumers of this cultivar, such an association is unlikely for sweet 'Golden Delicious' and it should be possible to develop a niche local market for such fruit.

\section{Literature Cited}

Boyer, J. and R.H. Liu. 2004. Apple phytochemicals and their benefits. Nutr. J. 3:5-20.

Crisosto, C.H., G.M. Crisosto, and E. Bowerman. 2003. Understanding consumer acceptance of peach, nectarine and plum cultivars. Acta Hort. 604:115-119.

Daillant-Spinnler, B., H.J.H. MacFie, P.K. Beyts, and D. Hedderley. 1996. Relationships between perceived sensory properties and major preference directions of 12 varieties of apples from the Southern hemisphere. Food Qual. Prefer. 7:113-126.

Demmig-Adams, B. and W.W. Adams, III. 1992. Photoprotection and other responses of plants to high light stress. Annu. Rev. Plant Physiol. Plant Mol. Biol. 50:333-359.

Dragsted, L.O., M. Strube, and J.C. Larsen. 1993. Cancer-protective factors in fruits and vegetables; biochemical and biological background. Pharmacol. Toxicol. 72:116-135.

Drogoudi, P.D., Z. Michailidis, and G. Pantelidis. 2008. Peel and flesh antioxidant content and harvest quality characteristics of seven apple cultivars. Sci. Hort. 115:149-153.

Drogoudi, P.D. and G. Pantelidis. 2011. Effect of position on canopy and harvest time on fruit physio-chemical and antioxidant properties in different apple cultivars. Sci. Hort. 129:752-760.

Fouché, J.R., S.C. Roberts, S.J.E. Midgley, and W.J. Steyn. 2010. Peel colour and blemishes in 'Granny Smith' apples in relation to canopy light environment. HortScience 45:899-905.

Fourie, P.C., C.F. Hansman, and H.M. Oberholzer. 1991. Sugar content of fresh apples and pears in South Africa. J. Agr. Food Chem. 39:1938-1939.

Foyer, C.H., M. Lelandais, and K.J. Kunert. 1994. Photooxidative stress in plants. Physiol. Plant. 92:696-717.
Hagen, S.F., G.I.A. Borge, G.B. Bengtsson, W. Bilger, A. Berge, K. Haffner, and K.A. Solhaug. 2007. Phenolic contents and other health and sensory related properties of apple fruit (Malus domestica Borkh., cv. Aroma): Effect of postharvest UV-B irradiation. Postharvest Biol. Technol. 45:1-10.

Harker, F.R. 2001. Consumer response to apples. Proc. Washington tree fruit postharvest conference. 31 May 2010. <http://postharvest.tfree. wsu.edu/ $>$.

Harker, F.R., B.T. Carr, M. Lenjo, E.A. MacRae, W.V. Wismer, and K.B. Marsh. 2009. Consumer liking for kiwifruit flavour: A metaanalysis of five studies on fruit quality. Food Qual. Prefer. 20:30-41.

Harker, F.R., J. Maindonald, S.H. Murray, F.A. Gunson, I.C. Hallett, and S.B. Walker. 2002. Sensory interpretation of instrumental measurements. 1. Texture of apple fruit. Postharvest Biol. Technol. 24:225-239.

Hirst, P.M., D.S. Tustin, and I.J. Warrington. 1990. Fruit colour responses of 'Granny Smith' apple to variable light environment. N. Z. J. Crop Hort. Sci. 18:205-214.

Iglesias, I., G. Echeverria, and Y. Soria. 2008. Differences in fruit colour development, anthocyanin content, fruit quality and consumer acceptability of eight 'Gala' apple strains. Sci. Hort. 119:32-40.

Jackson, J.E. 2003. Biology of horticultural crops: Biology of apples and pears. Cambridge University Press, Cambridge, UK.

Jaeger, S.R., Z. Andani, I.N. Wakeling, and H.J.H. MacFie. 1998. Consumer preferences for fresh and aged apples: A cross-cultural comparison. Food Qual. Prefer. 9:355-366.

Jaeger, S.R. and H.J.H. MacFie. 2001. The effect of advertising format and means-end information on consumer expectations for apples. Food Qual. Prefer. 12:189-205.

Jaeger, S.R., K.L. Rossiter, W.V. Wismer, and F.R. Harker. 2002. Consumer-driven product development in the kiwifruit industry. Food Qual. Prefer. 12:189-205.

Johnson, D.S. and M.S. Ridout. 2000. Effects on the quality of stored apple fruit, p. 67-84. In: Shewfelt, R.L. and B. Bruckner (eds.). Fruit and vegetable quality-An integrated view. Technomic, Lancaster, PA.

Johnson, J. and F.M. Clydesdale. 1982. Perceived sweetness and redness in coloured sucrose solutions. J. Food Sci. 47:747-752.

Johnson, J.L., F. Dzendolet, and F.M. Clydesdale. 1983. Psychophysical relationships between sweetness and redness in strawberry drinks. J. Food Prot. 46:21-25.

Johnson, J.L., F. Dzendolet, R. Damon, M. Sawyer, and F.M. Clydesdale. 1982. Psychophysical relationships between perceived sweetness and colour in cherry-flavoured beverages. J. Food Prot. 45:601-606.

Johnson, R.S. and A.N. Lakso. 1986. Carbon balance model of a growing apple shoot: 11 . Simulated effects of light and temperature on long and short shoots. J. Amer. Soc. Hort. Sci. 111:164-169.

Kang, N.J., K.W. Lee, S.J. Lee, C.Y. Lee, and H.J. Lee. 2004. Effects of phenolics in Empire apples on hydrogen peroxide-induced inhibition of gap-junctional intercellular communication. Biofactors 21:361-365.

Kays, S.J. 1998. Preharvest factors affecting appearance. Postharvest Biol. Technol. 15:233-247.

Lawless, H. and H. Heymann. 2010. Sensory evaluation of food. 2nd Ed. Springer, New York, NY.

Lee, K.W., Y.J. Kim, D.-O. Kim, H.J. Lee, and C.Y. Lee. 2003. Major phenolics in apple and their contribution to the total antioxidant capacity. J. Agr. Food Chem. 51:6516-6520.

Leong, L.P. and G. Shui. 2002. An investigation of antioxidant capacity of fruits in Singapore markets. Food Chem. 76:69-75.

Levene, H. 1960. Robust test in the equality of variance, p. 278-292. In: Contributions to probability and statistics. Stanford University Press, Iolkin, Palo Alto, CA.

Lewallen, K.S. and R.P. Marini. 2003. Relationship between flesh firmness and ground colour in peaches as influenced by light and canopy position. J. Amer. Soc. Hort. Sci. 128:163-170.

Lichtenthaler, H.K. 1987. Chlorophylls and carotenoids - Pigments of photosynthetic biomembranes. Methods Enzymol. 148:350-382.

Lila, M.A. 2004. Plant pigments and human health, p. 248-274. In: Davies, K.M. (ed.). Plant pigments and their manipulation. Annual Plant Reviews. Blackwell Publishing/CRC Press, Boca Raton, FL.

Ma, F. and L. Cheng. 2003. The sun exposed peel of apple fruit has higher xanthophyll cycle dependent thermal dissipation and antioxidants of the ascorbate glutathione pathway than the shaded peel. Plant Sci. 165:819-827.

Mancinelli, A.L., C.-P.H. Yang, P. Lindquist, O.R. Anderson, and I. Rabino. 1975. Photocontrol of anthocyanin synthesis. Plant Physiol. 55:251257.

Moyer, R.A., K.E. Hummer, C.E. Finn, B. Frei, and R.E. Wrolstad. 2002. Anthocyanins, phenolics and antioxidant capacity in diverse small fruits: Vaccinium, Rubus, and Ribes. J. Agr. Food Chem. 50:519-525.

Nilsson, T. and K.E. Gustavsson. 2007. Postharvest physiology of 'Aroma' apples in relation to position on the tree. Postharvest Biol. Technol. 43:36-46.

Olszowka, D., W. Maksymiec, Z. Krupa, and S. Krawezyk. 2003. Spectral analysis of pigment photobleaching in photosynthetic antenna complex LHCIIb. Photochem. Photobiol. B. Biol. 70:21-30.

Palmer, J.W., R.F. Harker, D.S. Tustin, and J. Johnston. 2010. Fruit dry matter concentration: A new quality metric for apples. J. Sci. Food Agr. 90:2586-2594.

Pollard, J., S.F.L. Kirk, and J.E. Cade. 2002. Factors affecting food choice in relation to fruit and vegetable intake. A review. Nutr. Rev. 15:373-387.

Rencher, A.C. 2002. Methods of multivariate analysis. 2nd Ed. John Wiley \& Sons Publication, New York, NY.

Robinson, T.L., E.J. Seeley, and B.H. Barrit. 1983. Effect of light environment and spur age on 'Delicious' apple fruit size and quality. J. Amer. Soc. Hort. Sci. 108:850-854.

Santos-Buelga, C. and A. Scalbert. 2000. Review. Proanthocyanidins and tannin-like compoundsNature, occurrence, dietary intake and effects on nutrition and health. J. Sci. Food Agr. 80: 1094-1117.

Saure, M.C. 1990. External control of anthocyanin formation in apple. Sci. Hort. 42:181-218.

Schechter, L. 2010. The apple and your eye: Visual and taste rank-order probit analysis with correlated errors. Food Qual. Prefer. 21:112-120.

Schrader, L.E., J. Zhang, and J. Sunday. 2003. Environmental stress that cause sunburn of apple. Acta Hort. 618:397-405.

Scurlock, J.M.O., S.P. Long, D.O. Hall, and J. Coombs. 1985. Introduction, p. xxi-xxiv. In: Coombs, I., D.O. Hall, S.P. Long, and J.M.O. Scurlock (eds.). Techniques in bioproductivity and photosynthesis. Pergamon Press, Oxford, UK. 
Shapiro, S.S. and M.B. Wilk. 1965. An analysis of variance test for normality (complete samples). Biometrika 52:591-611.

Slinkard, K. and V.L. Singleton. 1977. Total phenol analyses: Automation and comparison with manual methods. Amer. J. Enol. Viticult. 28:49-55.

Solomakhin, A. and M.M. Blanke. 2010. Can coloured hailnets improve taste (sugar, sugar: acid ratio), consumer appeal (colouration) and nutritional value (anthocyanin, vitamin C) of apple fruit. Food Sci. Technol. 43:1277-1284.

Steyn, W.J. 2012. Physiology and functions of fruit pigments: An ecological and horticultural perspective. Hort. Rev. 39:239-271.
Takos, A.M., F.W. Jaffe, S.R. Jacobs, J. Bogs, S.P. Robinson, and A.R. Walker. 2006. Light induced expression of $M Y B$ gene regulates anthocyanin biosynthesis in red apples. Plant Physiol. 142:1216-1232.

Telias, A., J.M. Bradeen, J.J. Luby, and E. Hoover. 2011. Regulation of anthocyanin accumulation in apple peel. Hort. Rev. 38:357-391.

Thybo, A.K., B.F. Kuhn, and H. Martens. 2004. Explaining Danish children's preference for apples using instrumental, sensory and demographic behavioural data. Food Qual. Prefer. 15:53-63.

Van der Merwe, A. 2013. Quantification of genotypic variation and consumer segmentation related to fruit quality attributes in appl (Malus domestica Borkh.). PhD diss., Stellenbosch Univ., Stellenbosch, South Africa.

Vinotur, Y. and V. Rodov. 2006. Method for determining total (hydrophilic and lipophilic) radical-scavenging activity in the same sample of fresh produce. Acta Hort. 709:53-60.

Warrington, I.J. 1994. The 'Granny Smith' apple. Fruit Var. J. 48:70-73.

Zampini, M., D. Sanabria, N. Phillips, and C. Spence. 2007. The multisensory perception of flavour: Assessing the influence of colour cues on flavour discrimination responses. Food Qual. Prefer. 18:975-984. 